\title{
Optimization of nitrided gate dielectrics by plasma-assisted and rapid thermal processing
}

\author{
G. Lucovsky ${ }^{\text {a) }}$ \\ Departments of Physics, Materials Science and Engineering, and Electrical and Computer Engineering, \\ North Carolina State University, Raleigh, North Carolina 27695 \\ H. Niimi \\ Department of Materials Science and Engineering, North Carolina State University, Raleigh, \\ North Carolina 27695 \\ Y. Wu, C. R. Parker, and J. R. Hauser \\ Department of Electrical and Computer Engineering, North Carolina State University, Raleigh, \\ North Carolina 27695
}

(Received 3 February 1998; accepted 9 March 1998)

\begin{abstract}
This article addresses several aspects of nitrogen atom ( $\mathrm{N}$ atom) incorporation into ultrathin gate oxides including: (i) monolayer incorporation of $\mathrm{N}$ atoms at the $\mathrm{Si}-\mathrm{SiO}_{2}$ interfaces to reduce tunneling currents and improve device reliability; and (ii) the incorporation of silicon nitride films into stacked oxide-nitride (ON) gate dielectrics to (a) increase the capacitance in ultrathin dielectrics without decreasing film thickness, and (b) suppress boron atom (B atom) diffusion from $p^{+}$polycrystalline $\mathrm{Si}$ gate electrodes through the dielectric layer to the Si substrate channel region. The results of this article demonstrate that these $\mathrm{N}$-atom spatial distributions can be accomplished by low thermal budget, single wafer processing which includes (i) low-temperature $\left(300{ }^{\circ} \mathrm{C}\right)$ plasma assisted oxidation, nitridation, and/or deposition to achieve the desired $\mathrm{N}$-atom incorporation, followed by (ii) low thermal budget $\left(30 \mathrm{~s}\right.$ at $\left.900{ }^{\circ} \mathrm{C}\right)$ rapid thermal annealing to promote chemical and structural bulk and interface relaxation. (C) 1998 American Vacuum Society.
\end{abstract}

[S0734-2101(98)58403-5]

\section{INTRODUCTION}

As the lateral dimensions of advanced Si field effect transistors (FETs) shrink into the deep submicron range $(d$ $<0.25 \mathrm{~nm}$ ), the oxide equivalent thickness $\left(t_{\text {ox eq }}\right)$ of gate dielectrics must decrease proportionally into an ultrathin regime $\left(t_{\text {ox eq }}<3 \mathrm{~nm}\right)$ in which direct tunneling becomes an important factor in the off-state leakage current. It has been demonstrated that $\mathrm{N}$ atoms can be incorporated into ultrathin gate dielectrics by (i) thermal, (ii) rapid thermal, and (iii) plasma-assisted processing. ${ }^{1-3}$ Interfacial $\mathrm{N}$-atom incorporation has been shown to improve device reliability. ${ }^{4}$ Incorporation of nitrogen in the bulk of the dielectric film in nitride layers has been shown to promote values of $t_{\mathrm{ox} \text { eq }}$ that are less than the physical thickness of the stacked dielectric as in ONO structures. ${ }^{5}$ Finally, $\mathrm{N}$-atom incorporation at the top surface of oxide dielectrics has been demonstrated to suppress $\mathrm{B}$-atom penetration from $p^{+}$polysilicon gate electrodes. ${ }^{6,7}$

This article describes a novel plasma-assisted process for $\mathrm{N}$-atom incorporation at $\mathrm{Si}-\mathrm{SiO}_{2}$ interfaces, and demonstrates that dielectrics with nitrided interfaces prepared in this way display reduced tunneling currents. The article also describes new results relative to the preparation and characterization of silicon nitride films prepared by remote plasmaassisted deposition. These films have been incorporated into $n$-channel FET devices with stacked ON dielectrics. ${ }^{8}$ The performance of these FETs with stacked ON gate dielectrics

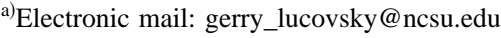

is compared with FETs with oxide dielectrics with the same $t_{\text {ox eq }}$. The suppression of B-atom diffusion from $p+$ polycrystalline silicon gate electrodes and accompanying improvements in device reliability are demonstrated for ultrathin nitride films, $t_{n} \sim 0.8 \mathrm{~nm}$ incorporated into stacked $\mathrm{ON}$ dielectrics. $^{7}$

\section{DEVICE FABRICATION}

\section{A. Nitrided interfaces}

It was previously shown that interface nitridation by plasma-assisted processing could be accomplished by a $300{ }^{\circ} \mathrm{C}$ plasma-assisted oxidation process in which $\mathrm{N}_{2} \mathrm{O}$ was used as the source gas for both initial oxide growth and interface nitridation. ${ }^{3,4}$ This process is the first of a two-step plasma process that has been used to fabricate device quality gate dielectrics. ${ }^{9}$ The second plasma processing step is a $300{ }^{\circ} \mathrm{C}$ remote plasma-assisted deposition of an oxide, ${ }^{3,4,9}$ or a stacked $\mathrm{ONO},{ }^{5}$ or $\mathrm{ON}$ structure. ${ }^{7,8}$ To obtain device quality performance and reliability, a post deposition rapid thermal anneal (RTA) at $900{ }^{\circ} \mathrm{C}$ for $30 \mathrm{~s}$ was required to promote bulk dielectric and interfacial chemical and structural relaxations, e.g., to evolve hydrogen from both oxide and nitride dielectrics and to reduce interfacial suboxide bonding. ${ }^{10}$ This article describes an alternative plasma-assisted oxidation/ nitridation process.

Figure 1 illustrates how this process is accomplished for $\mathrm{Si}(100)$ substrates by tracking the process sequence by online Auger electron spectroscopy. ${ }^{10}$ After an ex situ rinse in 


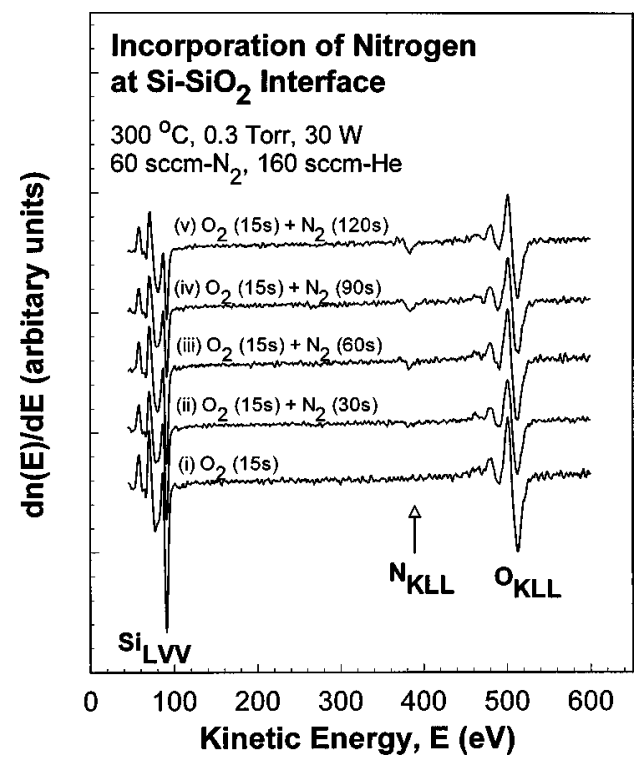

FIG. 1. Derivative AES spectra for interface nitridation times of 30, 60, 90, and $120 \mathrm{~s}$ following a $15 \mathrm{~s}$ plasma-assisted oxidation (Ref. 10).

dilute HF that (i) removes a thin sacrificial oxide layer and (ii) produces a hydrogen atom ( $\mathrm{H}$ atom) terminated surface, the first step in the process is a remote plasma-assisted oxidation (RPAO) using excited species (e.g., $\mathrm{O}_{2}^{*}$ ) extracted from a remote $\mathrm{He} / \mathrm{O}_{2}$ plasma. ${ }^{3,9,10}$ This step (i) accomplishes an in situ clean that reduces carbon and fluorine atom contamination, ${ }^{3}$ (ii) forms a $\mathrm{Si}-\mathrm{SiO}_{2}$ interface, and (iii) grows $\sim 0.5 \mathrm{~nm}$ of $\mathrm{SiO}_{2}$ which serves as a substrate layer for the deposition of a dielectric film. The $0.5 \mathrm{~nm}$ oxide film also prevents further oxidation of the $\mathrm{Si}$ substrate during plasmaassisted deposition of oxide layers. ${ }^{9}$ Interface nitridation is accomplished before deposition of the dielectric by exposure to the products from a remote $\mathrm{He} / \mathrm{N}_{2}$ plasma, primarily neutral $\mathrm{N}$ atoms. ${ }^{11}$ Systematic changes in the $\mathrm{N}_{\mathrm{KLL}}$ feature of the AES spectra in Fig. 1 demonstrate that the N-atom concentration in the dielectric increases with increasing plasma exposure time. Quantification of the rate at which $\mathrm{N}$ atoms are introduced in the dielectric will be discussed in the next section, where additional results from secondary ion mass spectrometry (SIMS) studies are presented.

Device structures were fabricated on these nitrided oxide interfacial oxide layers by completing the following additional steps: (i) $300{ }^{\circ} \mathrm{C}$ plasma-assisted deposition of $\mathrm{SiO}_{2}$ from remote plasma excitation of a $\mathrm{He} / \mathrm{O}_{2}$ and downstream injection of $\mathrm{SiH}_{4}, 3,9,10$ (ii) a $30 \mathrm{~s} 900^{\circ} \mathrm{C}$ rapid thermal anneal, ${ }^{10}$ (iii) formation of MOS capacitors using conventional photolithographic techniques following either (a) physical vapor deposition (PVD) of aluminum (Al) contacts, or (b) chemical vapor deposition, doping, and dopant activation of $n^{+}$polycrystalline silicon contacts. Following electrode deposition, there was a conventional 30 min postmetallization anneal (PMA) at $400{ }^{\circ} \mathrm{C}$ in a forming gas $\left(\mathrm{H}_{2} / \mathrm{N}_{2}\right)$ mixture. Interface characterization and device results are presented in Sec. III A.

\section{B. ON stacked gate dielectrics}

These were formed in two different ways. The gate stacks for the FETs were formed by the following in situ sequence: ${ }^{8}$ (i) $300^{\circ} \mathrm{C}$ plasma-assisted oxidation using a remote $\mathrm{He} / \mathrm{O}_{2}$ plasma to form $\sim 1.3 \mathrm{~nm}$ of oxide; (ii) deposition of $\sim 1.3 \mathrm{~nm}$ of hydrogenated silicon nitride by a $300{ }^{\circ} \mathrm{C}$ remote plasmaassisted deposition process using $\mathrm{SiH}_{4}$ and $\mathrm{NH}_{3}$ as the source gases; (iii) a vacuum anneal at $900{ }^{\circ} \mathrm{C}$ for $30 \mathrm{~s}$; and (iv) an on-line deposition of polycrystalline $\mathrm{Si}$ for the gate electrode. The remainder of the FET structure was formed by conventional processing techniques. A source gas ratio of $\mathrm{NH}_{3}: \mathrm{SiH}_{4}$ of $\sim 10: 1$ that previously gave optimum electrical performance in devices with ONO structures was used in the nitride deposition step. ${ }^{11}$ Device results are presented in Sec. III $C$ following a discussion of the unique properties of the plasma deposited nitride films in Sec. III B.

The MOS capacitors for the B-diffusion studies were fabricated on $5 \Omega \mathrm{cm}(100) n$-type $\mathrm{Si}$ substrates with previously grown oxide gate dielectrics. ${ }^{7}$ Gate oxides in the range from $\sim 3$ to $\sim 6 \mathrm{~nm}$ were grown by furnace oxidation in dry $\mathrm{O}_{2}$ at $800{ }^{\circ} \mathrm{C}$. This was followed by deposition of nitride films $0.4-0.8 \mathrm{~nm}$ thick by $300{ }^{\circ} \mathrm{C}$ remote plasma-assisted process. The nitride layer thickness estimated by on-line AES, and confirmed by spectroscopic ellipsometry. The nitride deposition was followed by a $30 \mathrm{~s} 900{ }^{\circ} \mathrm{C}$ RTA. Undoped polycrystalline silicon, prepared by a conventional low pressure chemical vapor deposition (LPCVD) process with a thickness of $\sim 200 \mathrm{~nm}$, was deposited following the gate dielectric RTA. Boron implantation into the polysilicon was performed at $12 \mathrm{keV}$ to a dose of $5 \times 10^{15} \mathrm{~cm}^{-2}$; this was followed by an aggressive drive-in anneal in argon for $4 \mathrm{~min}$ at $1000{ }^{\circ} \mathrm{C}$ which activated and redistributed the implanted B atoms. MOS capacitors for electrical testing were completed by conventional metallization, patterning and postmetallization annealing processes. Electrical results for these PMOS device structures are presented in Sec. III D.

\section{EXPERIMENTAL RESULTS}

\section{A. Interface characterization and tunneling studies}

Figures 2(a) and 2(b) present the results of SIMS measurements made at Evans East on a stacked dielectric comprised of the nitrided interface and template film, $\sim 0.5-0.6$ $\mathrm{nm}$ thick, and a $\sim 5 \mathrm{~nm}$ plasma-deposited $\mathrm{SiO}_{2}$ film. The nitrided interface then is $\sim 5.5-6 \mathrm{~nm}$ below the film surface. The SIMS determination of $\mathrm{N}$ was made by counting both $\mathrm{SiN}^{-}$and $\mathrm{CsN}^{+}$ions during the sputtering process. The profiles of these ions indicate that the $\mathrm{N}$ atoms are incorporated in the immediate vicinity of the $\mathrm{Si}-\mathrm{SiO}_{2}$ interface, and differences in the profiles are associated with the drive-in of the $\mathrm{N}$ atoms into the $\mathrm{Si}$ substrate during the SIMS measurements. Figures 3(a) and 3(b) indicate that the normalized SIMS signals of Figs. 2(a) and 2(b), respectively, display a linear dependence as function of nitridation time. In addition, based on normalization procedures discussed in Ref. 3, the 


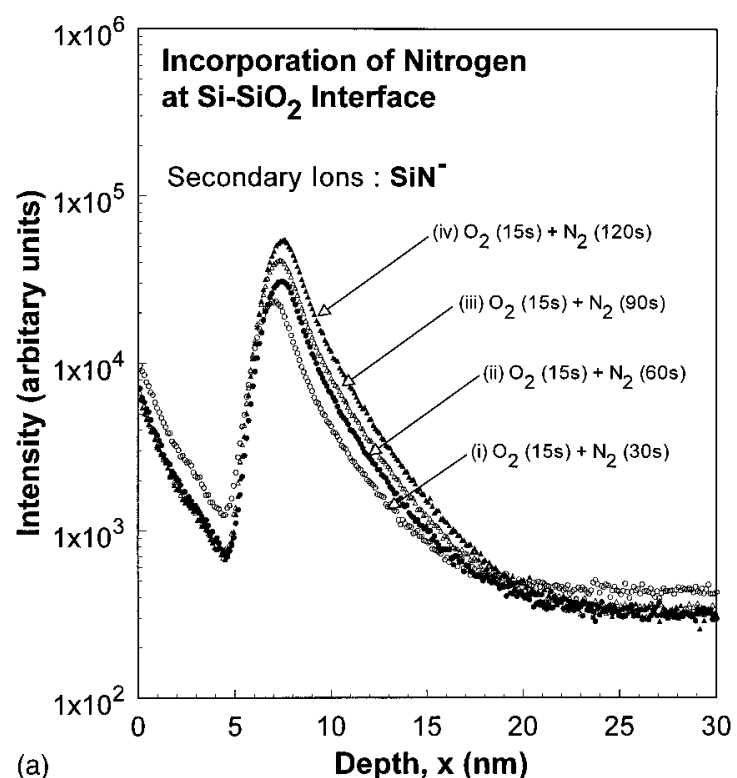

(a)

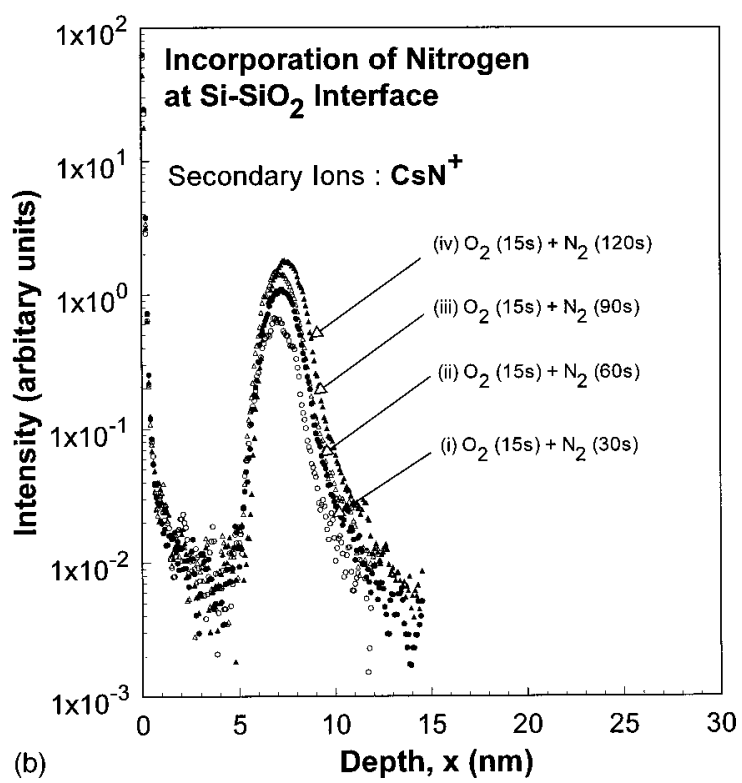

FIG. 2. SIMS data on nitride interfaces as a function of nitridation time (see Fig. 1), by detection of (a) $\mathrm{SiN}^{-}$ions and (b) $\mathrm{CsN}^{+}$ions. The strong rise of the $\mathrm{N}$-signal marks the interface between the dielectric and a crystalline $\mathrm{Si}$ substrate.

interface concentration of $\mathrm{N}$ atoms attains a monolayer coverage $( \pm 10 \%)$ after a $90 \mathrm{~s}$ exposure to the $\mathrm{He} / \mathrm{N}_{2}$ plasma process described above.

Figure 4 contains a plot of the ratio of the amplitudes of $\mathrm{N}_{\mathrm{KLL}}$ and substrate $\mathrm{Si}_{\mathrm{LVV}}(91 \mathrm{eV})$ features versus nitridation time. A plot of the $\mathrm{N}_{\mathrm{KLL}}$ strength versus time shows a sublinear dependence. However, plotting the data as a ratio also yields a linear dependence of the nitrogen concentration versus nitridation time. The use of the $\mathrm{N} / \mathrm{Si}$ ratio demonstrates that the $\mathrm{N}$ atoms are at the $\mathrm{Si}-\mathrm{SiO}_{2}$ interface, which is then more accurately characterized as a $\mathrm{Si}-\mathrm{N}-\mathrm{SiO}_{2}$ interface. Since the $91 \mathrm{eV} \mathrm{Si} i_{L V V}$ features comes from the substrate, normalization of the $\mathrm{N}_{\mathrm{KLL}}$ signal takes into account passage of the $\mathrm{N}_{\mathrm{KLL}}$ electrons through the oxide film, and the in-
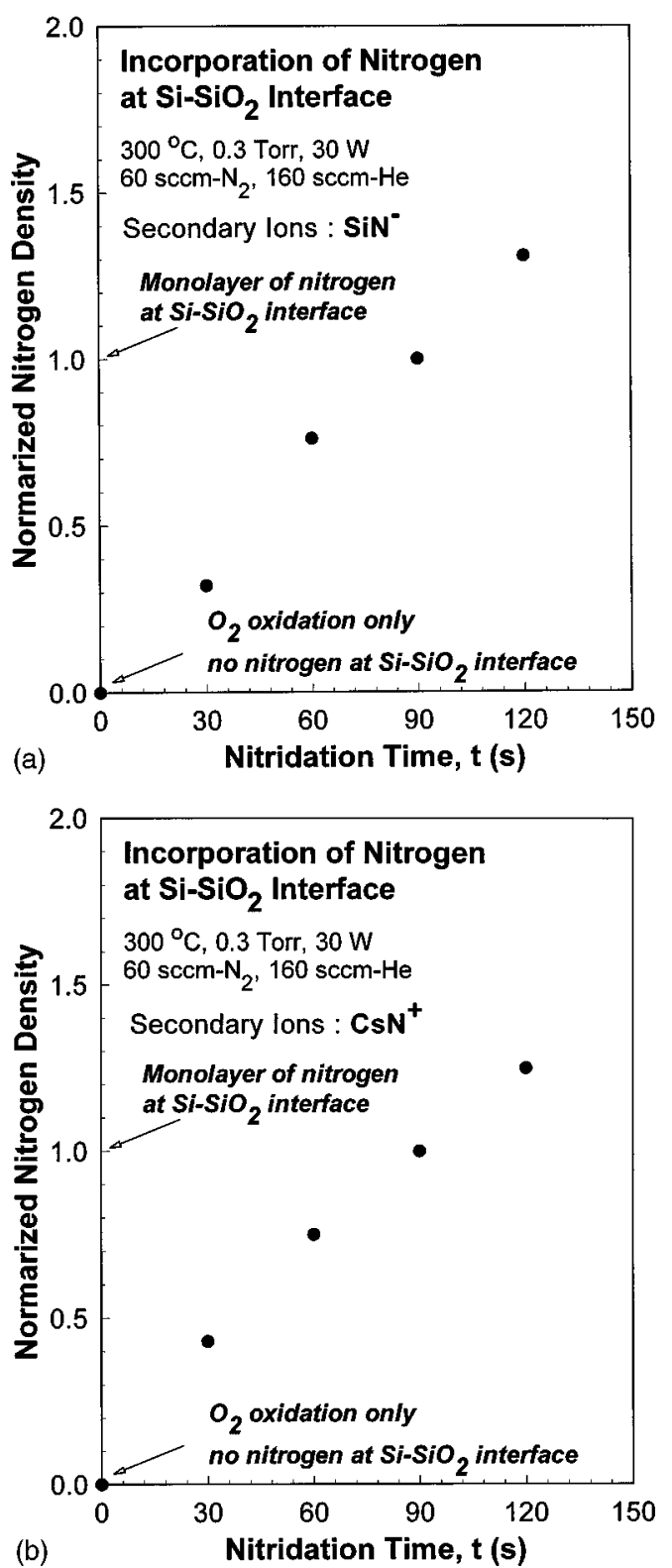

FIG. 3. Normalized plots of integrated ion counts vs time: (a) $\mathrm{SiN}^{-}$ions and (b) $\mathrm{CsN}^{+}$ions. A normalized count of 1 corresponds to an $\sim 1$ monolayer of interfacial $\mathrm{N}$ atoms.

crease in overall film thickness as $\mathrm{N}$ atoms are incorporated at the $\mathrm{Si}-\mathrm{SiO}_{2}$ interface. Note that the escape depth for AES electrons with energies of $90 \mathrm{eV}$ is approximately $0.6 \mathrm{~nm}$. Since the SIMS data indicate a linear dependence of $\mathrm{N}$-atom incorporation with time, the normalized plotting of the AES data establishes the $\mathrm{N}$ atoms are at the interface, rather than in the bulk of the plasma grown oxide layer.

Figures 5(a) and (b) are current density-voltage $(J-V)$ plots for the MOS capacitors with nitrided interfaces and $n$-type substrates described in Sec. II A. The plot in Fig. 5(a) is for an oxide thickness of $\sim 5 \mathrm{~nm}$. This sample has an $\mathrm{Al}$ gate electrode, and the $J-V$ plot is for substrate injection. The current below about $3 \mathrm{~V}$ is displacement current associated with the ramped voltage that was used in the $J-V$ data acquistion. The tunneling currents for voltages approxi- 


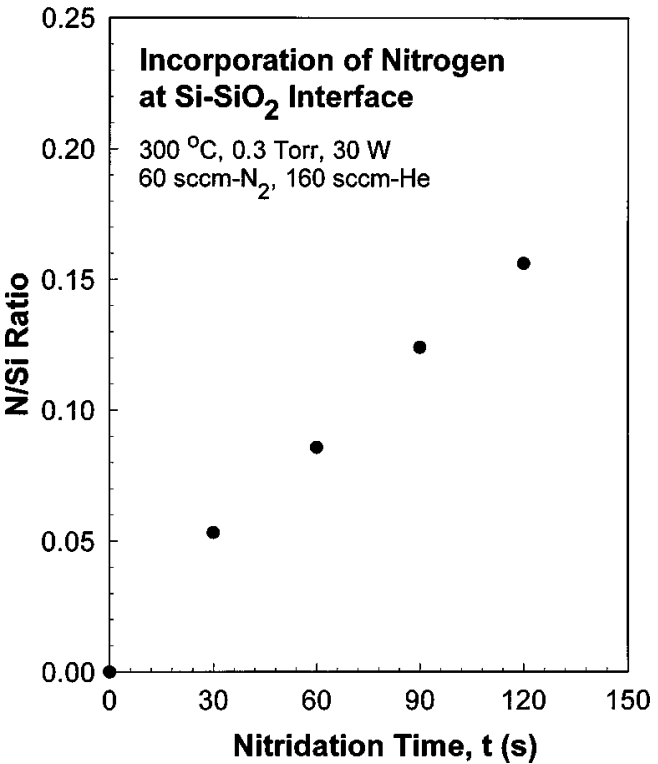

FIG. 4. Plot of the ratio of the amplitudes of $\mathrm{N}_{\mathrm{KLL}}$ and substrate $\mathrm{Si}_{\mathrm{LVV}}(91$ $\mathrm{eV})$ features vs nitridation time.

mately $3 \mathrm{~V}$ and above are associated with a FowlerNordheim tunneling process. These tunneling currents decrease as the time of nitridation increases, and hence as the interfacial nitrogen concentration increases. For a fullynitrided interface, the tunneling current is reduced by approximately an order of magnitude by the interface nitridation with respect to a non-nitrided interface. Similar reductions in tunneling current density are also observed for direct tunneling as in Fig. 5(b) which displays $J-V$ plots for oxide thickness of approximately 2 and $3.0 \mathrm{~nm}$. These samples have $n^{+}$polycrystalline $\mathrm{Si}$ gate electrodes and the $J-V$ plots are also for substrate injection. It is important to note that the flat-band voltages for the MOS structures of Figs. 5(a) and 5(b), do not vary by more than $0.05 \mathrm{eV}$, so that the changes in the $J-V$ plots represent decreased current flow, and are not a result of differences in zero-bias built-in electric fields. Finally, similar results have been obtained for samples with $p$-type substrates and oxide thicknesses of $\sim 5$ $\mathrm{nm}$. For these samples, tunneling currents for gate injection were also reduced by approximately a factor of 10 as interface nitridation increased to the ones monolayer level. As in the case of the MOS devices prepared on $n$-type substrates, the flat-band voltages for the MOS capacitors prepared on $p$-type substrates also displayed a change of no more than $\sim 0.05 \mathrm{eV}$ between the non-nitrided and fully-nitrided interfaces.

\section{B. Characterization of plasma deposited nitrides}

The hydrogenated plasma deposited nitrides have been characterized by infrared (IR) absorption measurements. ${ }^{12}$ IR spectra indicated features due to: (i) the $\mathrm{Si}-\mathrm{N}$ asymmetric bond-stretching vibration at $\sim 850 \mathrm{~cm}^{-1}$; (ii) the bondstretching vibration of the $\mathrm{N}-\mathrm{H}$ group at $\sim 3350 \mathrm{~cm}^{-1}$; (iii) the bond-bending vibration of the $\mathrm{N}-\mathrm{H}$ group at $\sim 1150$
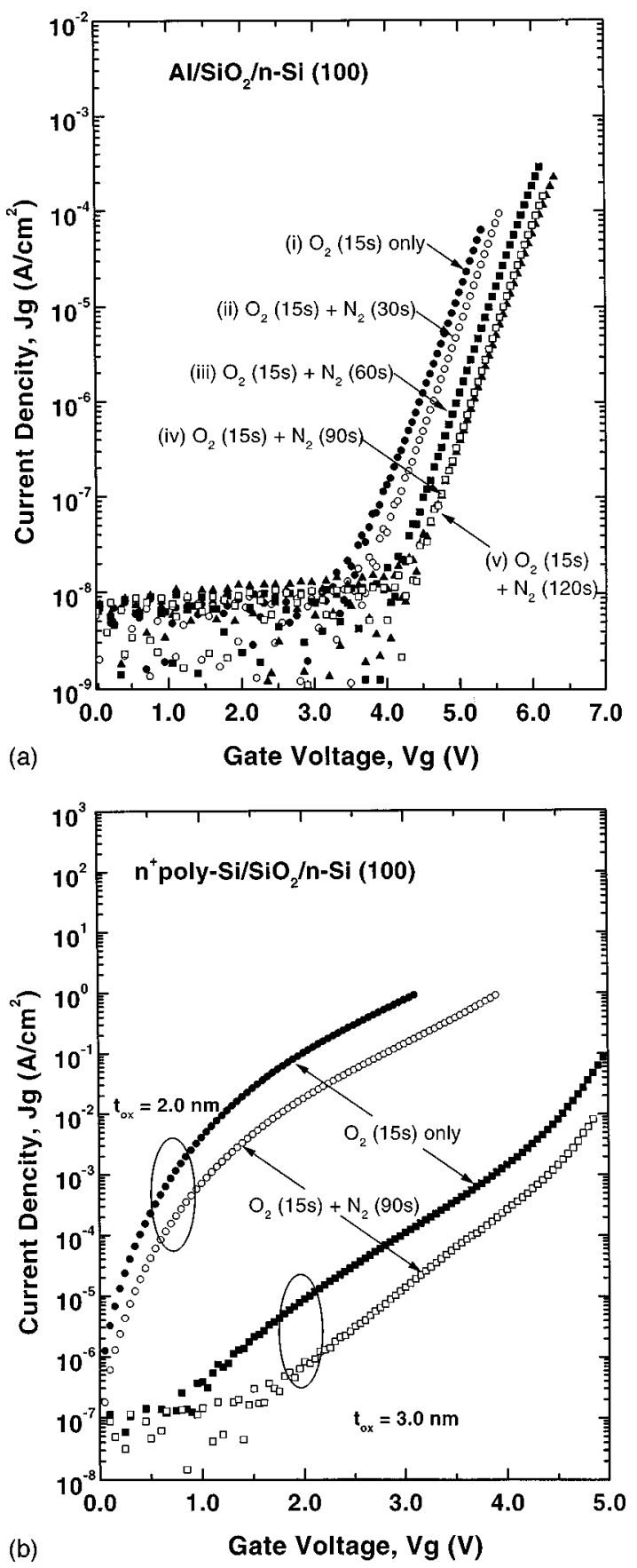

FIG. 5. (Current-density)-voltage $(J-V)$ characteristics for substrate for NMOS capacitors: (a) with $\sim 5 \mathrm{~nm}$ thick oxide layers, Al gate electrodes, and with (i) non-nitrided, (ii) and (iii) partially nitrided, and (iv) and (v) fully nitrided interfaces as discussed with respect with Figs. 1-4; and (b) for capacitors with $\sim 2$ and $3.0 \mathrm{~nm}$ oxide layers, with $n^{+}$polysilicon gate electrodes for non-nitrided and fully nitrided interfaces.

$\mathrm{cm}^{-1}$, and (iv) the bond-stretching vibration of the $\mathrm{Si}-\mathrm{H}$ group at $\sim 2170 \mathrm{~cm}^{-1}$. Films deposited at $300{ }^{\circ} \mathrm{C}$ from different source gas mixtures of $\mathrm{NH}_{3} / \mathrm{SiH}_{4}$ established that beginning at about $400{ }^{\circ} \mathrm{C}$ hydrogen was evolved from the film. The loss of $\mathrm{H}$ atoms could be described by a temperatureactivated process with an activation of $\sim 0.4 \mathrm{eV}$. This was consistent with $\mathrm{H}$-atom loss being associated with processes in which molecular $\mathrm{H}_{2}$ was formed. For example, it was 

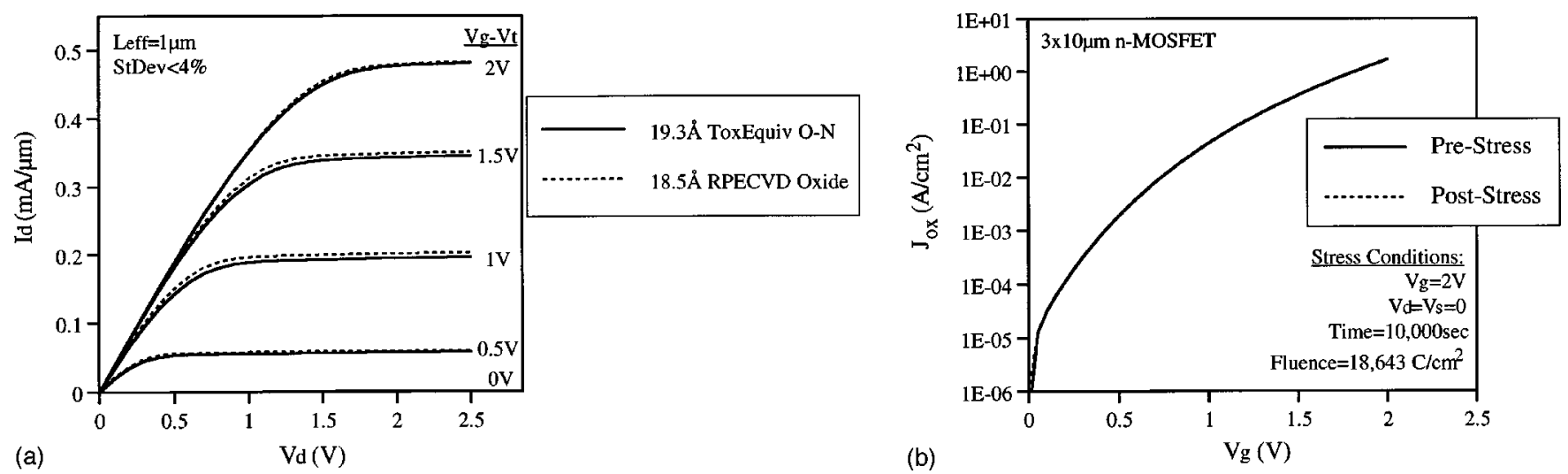

FIG. 6. (a) Current-voltage characteristics of FETs with ultrathin oxide and stacked ON gate dielectrics. (b) Reliability for ultrathin FETs with stacked ON gate dielectrics.

demonstrated that the hydrogenated silicon nitride films contained nearest-neighbor $\mathrm{Si}-\mathrm{H}-\mathrm{H}-\mathrm{N}-\mathrm{Si}$ bonding arrangements, and that there were significant decreases in the both the $\mathrm{Si}-\mathrm{H}$ and $\mathrm{N}-\mathrm{H}$ vibrational signatures with annealing. ${ }^{12,13}$ A reaction pathway for $\mathrm{H}$-atom evolution that is suggested by these results is

$$
\mathrm{Si}-\mathrm{H}-\mathrm{H}-\mathrm{N}-\mathrm{Si} \rightarrow \mathrm{Si}^{0}+{ }^{0} \mathrm{~N}-\mathrm{Si}+\mathrm{H}_{2} \text {, }
$$

where the superscript notation $\left({ }^{0}\right)$ indicates a neutral dangling bond, and the $\mathrm{H}-\mathrm{H}$ notation indicates nearest network neighbors. In the temperature range to about $500-600{ }^{\circ} \mathrm{C}$, the only significant changes in the IR were decreases in the amplitudes of the $\mathrm{Si}-\mathrm{H}$ and $\mathrm{N}-\mathrm{H}$ vibrations, whereas at temperatures greater than about $600^{\circ} \mathrm{C}$, there was a systematic increase in the amplitude of the $\mathrm{Si}-\mathrm{N}$ feature. The combination of these results for annealing temperature $>600{ }^{\circ} \mathrm{C}$ suggests that as $\mathrm{H}$ atoms were evolved from the films, new $\mathrm{Si}-\mathrm{N}$ bonds were formed. This is represented symbolically in Eqs. (2a) and (2b):

$$
\begin{aligned}
& \mathrm{Si}-\mathrm{H}-\mathrm{H}-\mathrm{N}-\mathrm{Si} \rightarrow \mathrm{Si}^{0}+{ }^{0} \mathrm{~N}-\mathrm{Si}+\mathrm{H}_{2}, \\
& \mathrm{Si}^{0}+{ }^{0} \mathrm{~N}-\mathrm{Si} \rightarrow \mathrm{Si}-\mathrm{N}-\mathrm{Si} .
\end{aligned}
$$

The as-deposited films also contain SiNH groups in two other bonding arrangements: (i) in nearest-neighbor pairs, where they interact via H-bonding interactions, and (ii) as isolated bonding groups where the $\mathrm{H}$ atoms of the $\mathrm{N}$ group interact with near-neighbor $\mathrm{N}$ atoms of the network. The interactions in (ii) are also H-bonding-type interactions, and the distribution of near-neighbor $\mathrm{N}$ atoms is determined by the local network bonding at the particular $\mathrm{N}-\mathrm{H}$ site. Loss of hydrogen with the subsequent evolution of different $\mathrm{N}-\mathrm{H}$ bonding groups such as $\mathrm{N}-\mathrm{H}_{2}$ can occur from the nearest neighbor pairs, with reaction pathways being similar to those described in Eqs. (1) and (2). Loss of $\mathrm{H}$ atoms from the isolated $\mathrm{N}-\mathrm{H}$ groups is considerably less likely due to the relatively high $\mathrm{N}-\mathrm{H}$ bond energy, of the order of $5 \mathrm{eV}$.

As noted in Sec. II, a source gas ratio of $\mathrm{NH}_{3}: \mathrm{SiH}_{4}$ of $\sim 10: 1$ gave optimum electrical performance. Combining IR and AES data with a statistical model of bonding in amorphous Si:N:H alloys indicates that this source gas ratio cor- responds to a film in which the respective silicon, nitrogen, and hydrogen concentrations are $[\mathrm{Si}] \sim 28$ at. $\%,[\mathrm{~N}] \sim 42$ at. $\%$, and $[\mathrm{H}] \sim 30$ at. $\%{ }^{14}$ It was shown in Ref. 14 , that the average number of bonds/atom for this composition is $\sim 2.7$, the same as in device-quality plasma-deposited $\mathrm{SiO}_{2}$ films. In addition, hydrogenated silicon nitride films with this composition have been used in amorphous silicon thin film transistors as the gate dielectrics and yielded optimized electrical performance. For example, transconductance electron mobilities of $\sim 1.5 \mathrm{~cm}^{2} \mathrm{~V}^{-1} \mathrm{~s}^{-1} 15$ were obtained indicating a low concentration of charged defect centers. For both lower and higher source gas ratios, the film composition changed and the effective channel mobility decreased. This behavior has been interpreted as being a manifestation of the similarity in bonding statistics to $\mathrm{SiO}_{2}$ as noted earlier in this paragraph.

\section{Electrical performance of FETs with ON dielectrics}

Figures 6(a) and 6(b) present data on the performance and reliability of FETs incorporating stacked ON gate dielectrics. ${ }^{8}$ These data have been discussed in more detail in Ref. 8. In summary, the approximate electrical thickness of the gate dielectrics was obtained to $\pm 1 \AA$ from analysis of capacitance-voltage $(C-V)$ data. TEM micrographs of the composite ON structures indicated approximately equal oxide and nitride layer thickness. Based on an approximately 1:2 ratio of silicon nitride to silicon oxide static dielectric constants, this means that a $1.8 \pm 0.1 \mathrm{~nm} \mathrm{ON}$ film is comprised of oxide and nitride layers which are each approximately $1.2 \pm 0.1 \mathrm{~nm}$ thick. The transistor characteristics, drain current, $I_{d}$, versus drain bias voltage, $V_{d}$, plotted for different normalized gate voltages $\left(V_{g}-V_{t h}\right.$, where $V_{g}$ is the gate voltage and $V_{t h}$ is the threshold voltage). Since the $I_{d}$ is proportional to the inversion capacitance, the equality of the drain currents for the two devices is consistent with their having the same oxide equivalent dielectric thickness. Figure 6(a) demonstrates that the FET with the ON dielectric performs as well as a FET with an oxide dielectric. The oxide dielectric in this case was formed by a combination of (i) $300^{\circ} \mathrm{V}$ remote plasma-assisted oxidation and deposition, and 
(ii) an in situ vacuum anneal at $900{ }^{\circ} \mathrm{C}$ for $30 \mathrm{~s}$. The current voltage plots in Fig. 6(b) indicate the robust nature of the ON gate dielectric, i.e., there is no detectable degradation after an integrated current exposure equivalent to about 1.6 $\times 10^{4} \mathrm{C} \mathrm{cm}^{-2}\left(V_{g}=2.0 \mathrm{~V}\right)$. Finally, the direct tunneling current for the FET with the ON dielectric was reduced by a factor of $\sim 5-7$ with respect to that of the FET with oxide dielectric.

\section{Boron penetration studies for ON films}

Quasi-static $C-V$ curves were compared in Fig. 7(a) for MOS capacitors (i) with a control thermal oxide, and (ii) with composite oxide-nitride dielectrics with $0.4 \mathrm{~nm}$, and $0.8 \mathrm{~nm}$ thick nitride layers. The $C-V$ curve for the control oxide shifted significantly to a relatively high flatband voltage, $V_{\mathrm{FB}}$ as compared to nitride-deposited devices indicating a large amount of B atom penetration has occurred. This was confirmed by preparing capacitors with $\mathrm{Al}$ gate electrodes on the different gate dielectrics used above, i.e., the control thermal oxide, and the composite oxide-nitride dielectrics. The flatband voltages for these NMOS structures were obtained from $C-V$ measurements and were also essentially the same, $-0.82 \pm 0.1 \mathrm{~V}$. Using these results enabled us to determine an anticipated value for using a B-atom doped polycrystalline $\mathrm{Si}$ gate electrode in a PMOS structure. One of the most important aspects of this comparative study on NMOS structures was the consistency of the flatband voltages for the different gate dielectric structures. This consistency means that introducing the nitride films on the oxide substrate did not introduce fixed charge at either the $\mathrm{Si}-\mathrm{SiO}_{2}$ interface, or the internal interface between the nitride and oxide constituents of the dual layer dielectrics similar to what had been found in our earlier studies tri-layer oxide-nitride-oxide dielectrics which were made using essentially the same sequence of plasma and rapid thermal annealing process steps. ${ }^{15}$ The anticipated $V_{\mathrm{FB}}$ is approximately $+0.7 \mathrm{~V}$, and $V_{\mathrm{FB}}$ for the control oxide is shifted to approximately $+1.1 \mathrm{~V}$. The $V_{\mathrm{FB}}$ value for the capacitor with the $0.8 \mathrm{~nm}$ nitride is at approximately $+0.7 \mathrm{eV}$ indicating essentially no boron penetration to the underlying $n$-type $\mathrm{Si}$ substrate. $V_{\mathrm{FB}}$ for the device with the $0.4 \mathrm{~nm}$ top nitride is intermediate, approximately $+0.8 \mathrm{~V}$, which shows the degree of boron penetration is controllable for a fixed thermal budget by changing the deposited nitride layer thickness. Oxide reliability was examined by measuring charge to breakdown $\left(Q_{\mathrm{BD}}\right)$ under constant Fowler-Nordheim current stressing as shown in Fig. 7(b). Each experimental point is the average of 15 device runs. $Q_{\mathrm{BD}}$ was highest for film with the thickest top nitride layer. The relative decreases in $Q_{\mathrm{BD}}$ in capacitors with the control oxide, and the composite dielectric with the $0.4 \mathrm{~nm}$ nitride layer are attributed to boron penetration. The $Q_{\mathrm{BD}}$ value of the capacitor with the $0.8 \mathrm{~nm}$ top nitride is twice as high as that of the capacitor with the control oxide. As a point for reference, the $Q_{\mathrm{BD}}$ values for MOS capacitors with Al-gate electrodes were found to be essentially the same as that of the capacitor with the dual layer oxide-nitride dielec-
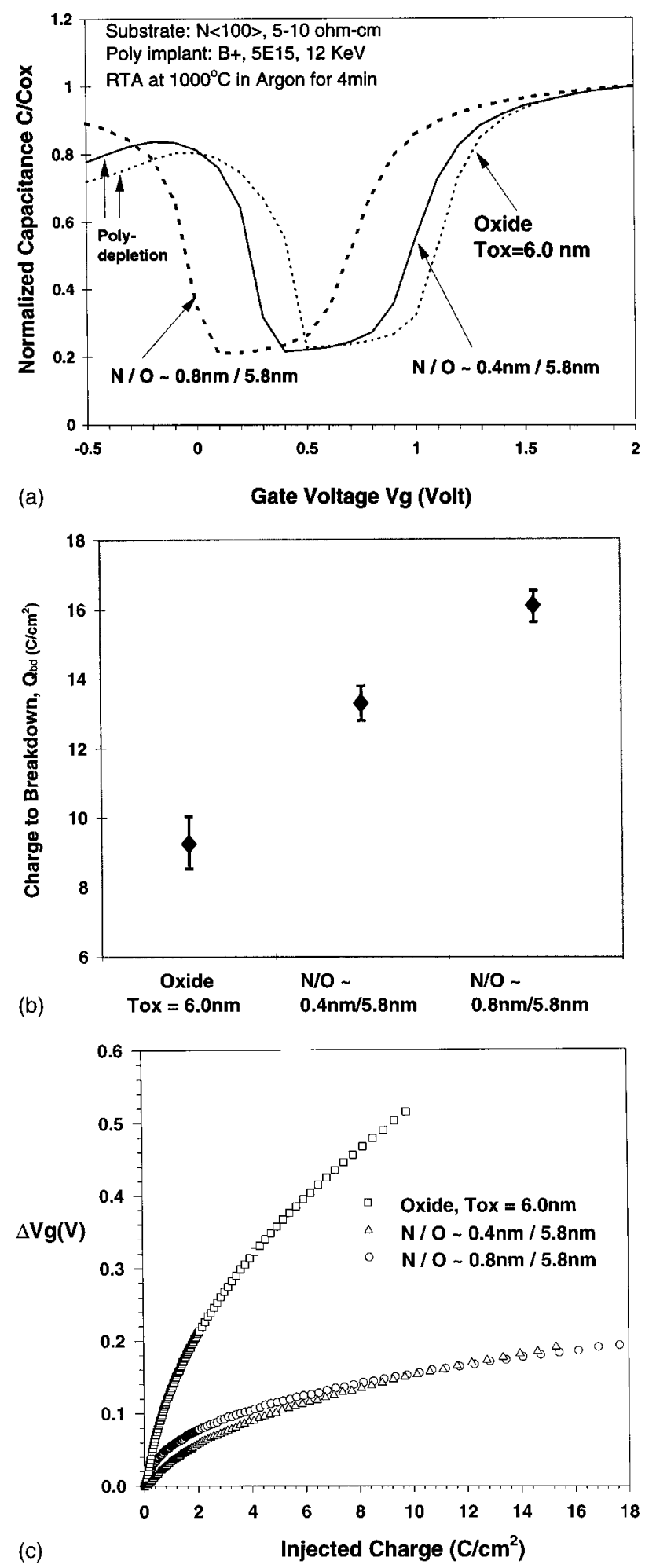

FIG. 7. Date for PMOS devices with $\sim 5-6 \mathrm{~nm}$ dielectrics: (a) Normalized quasistatic $C-V$ curves for MOS capacitors with different thickness of top nitride layers: $t_{n}=0.0,0.4$, and $0.8 \mathrm{~nm}$; (b) charge to breakdown (QBD) for $50 \%$ failure under constant current substrate injection at $100 \mathrm{~mA} \mathrm{~cm}^{-2}$; and (c) applied gate voltage shifts, $d V_{g}$ during the same constant current substrate injection as in (b).

tric with the $0.8 \mathrm{~nm}$ nitride. Figure 7(c) shows applied gate voltages shifts as a function of injected charge. The reliability of the devices with the top surface nitride layers is clearly improved. 


\section{DISCUSSION}

This section is divided into three parts which address, respectively: (i) the reduction of tunneling currents in MOS capacitors with nitrided interfaces; (ii) the unique character of the nitride films formed by the two step process sequence of $300{ }^{\circ} \mathrm{C}$ deposition by remote plasma-assisted deposition followed by a vacuum or inert ambient RTA for $30 \mathrm{~s}$ at $900{ }^{\circ} \mathrm{C}$; and (iii) the suppression of nitrogen diffusion through ultrathin nitride layers.

\section{A. Nitrided interfaces}

The $J-V$ data in Figs. 5(a) and 5(b) in Sec. III A indicate significant decreases in tunneling current density with increasing interface nitridation. At first sight this result is surprising since the $\mathrm{Si}-\mathrm{SiO}_{2}$ conduction band off-set energy is significantly higher than the $\mathrm{Si}-\mathrm{Si}_{3} \mathrm{~N}_{4}$ conduction band offset energy, $\sim 3.1 \mathrm{eV}$ as compared to $2.1 \mathrm{eV},{ }^{16}$ suggesting that interfacial nitridation would be expected to increase tunneling currents. The nearly constant reduction of tunneling current for thicknesses in the Fowler-Nordheim regime as in Fig. 5(a), and in the direct tunneling regime as in Fig. 5(b), as well as the fact that similar reductions occur for both substrate and gate injection, indicates that the reduction is not simply due to changes in effective oxide thickness, or the direction of current injection. Flat-band voltages, obtained from analysis of $C-V$ curves have indicated a small variation of flat-band voltage with interface nitridation $(<0.05 \mathrm{~V})$, demonstrating that built-in oxide fields were not the cause of the current reductions. In addition, a newly developed model for band off-set energies that includes the effects of charge transfer interface dipoles places an upper limit on the possible flat band voltage shifts ${ }^{17}$ of $\sim 0.1 \mathrm{eV}$ that supports to the results of the $C-V$ and $J-V$ studies.

Studies of $\mathrm{Si}-\mathrm{SiO}_{2}$ interfaces have shown that the oxidation of $\mathrm{Si}$ invariably results in transition regions with excess suboxide bonding between the crystalline $\mathrm{Si}$ substrate and the $\mathrm{SiO}_{2} \cdot{ }^{18}$ If $\Phi_{\mathrm{ms}}$ is the metal-semiconductor work function in the absence of interfacial dipoles, then the effective metalsemiconductor work function for a non-nitrided interface with interfacial $\mathrm{Si}-\mathrm{O}$ bonds, $\Phi_{\mathrm{ms}}^{\prime}(\mathrm{Si}-\mathrm{O})$, is given by:

$$
\Phi_{\mathrm{ms}}^{\prime}(\mathrm{Si}-\mathrm{O})=\Phi_{\mathrm{ms}}-V_{\text {dipole }}(\mathrm{Si}-\mathrm{O}),
$$

where $V_{\text {dipole }}(\mathrm{Si}-\mathrm{O})$ is the potential energy step associated with interfacial dipoles. This potential energy step adds to the conduction band offset as determined from vacuum levels. In Ref. 17, it is demonstrated that $V_{\text {dipole }}(\mathrm{Si}-\mathrm{O})$ depends on the nature of the bonding at the $\mathrm{Si}-\mathrm{SiO}_{2}$ interface. The dipole step is greater for an abrupt $\mathrm{Si}-\mathrm{SiO}_{2}$ interface, $V_{\text {dipole }}\left(\mathrm{Si}-\mathrm{O}_{\text {abrupt }}\right)$, than for an interface with suboxide bonding, $V_{\text {dipole }}\left(\mathrm{Si}-\mathrm{O}_{\text {suboxide }}\right)$. In addition, it was shown that the dipole step is greater for a nitrided $\mathrm{Si}-\mathrm{N}-\mathrm{SiO}_{2}$ interface than for an interface with significant suboxide bonding as has been reported for $\mathrm{Si}-\mathrm{SiO}_{2}$ interfaces even after a $30 \mathrm{~s} 900{ }^{\circ} \mathrm{C}$ RTA. The difference in the height of the potential barrier between a nitrided interface and an interface with suboxide bonding is given by

$$
\delta V=V_{\text {dipole }}(\mathrm{Si}-\mathrm{N})-V_{\text {dipole }}\left(\mathrm{Si}-\mathrm{O}_{\text {suboxide }}\right) .
$$

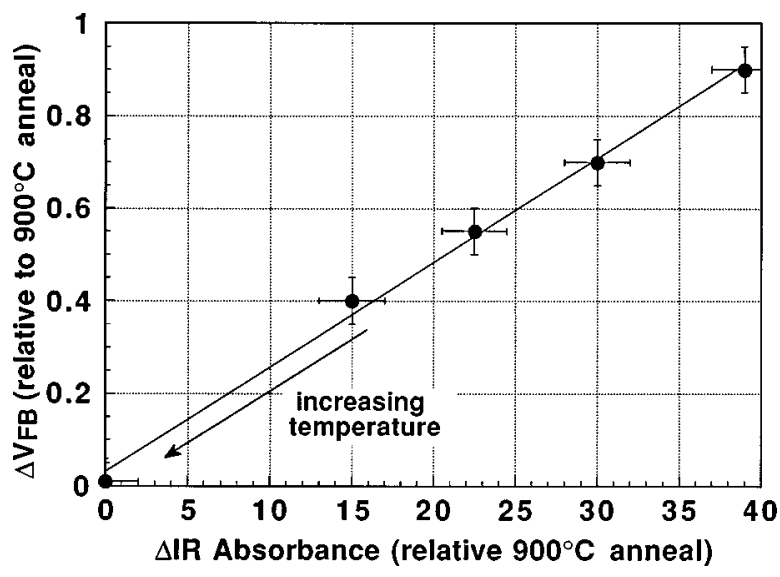

FIG. 8. Decreases in $V_{t h}$ as a function of increases in peak IR absorption strength in $\mathrm{Si}-\mathrm{N}$ bond-stretching mode. The arrow in the figure indicates the direction of increased annealing temperatures. Data are normalized with respect to values at $900{ }^{\circ} \mathrm{C}$.

The calculations of Ref. 18 show that $\delta V$ at most equal to 0.1 $\mathrm{eV}$ so that the barrier height is not significantly different for an abrupt nitrided interface and for a $\mathrm{Si}-\mathrm{SiO}_{2}$ interface that has a minimized degree of suboxide bonding after a $900{ }^{\circ} \mathrm{C}$ RTA. The driving force for dipole formation is an equalization of a chemical potential that can be obtained from considerations of the relative electronegativities of the interfacial bonding arrangements. Under this driving force, electrons are transferred from the $\mathrm{Si}$ substrate to the dielectric. The magnitude of the charge transfer is $\sim 0.1-0.2 e$, where $e$ is the charge on the electron. ${ }^{17}$ This analysis supports the results of the $C-V$ and $J-V$ measurements of Sec. III A; i.e., that the changes in tunneling currents are not due to systematic changes in built in fields, associated with changes in flat band voltages.

Therefore, an alternative mechanism must be invoked to explain the tunneling results. One way to interpret the data in Figs. 5(a) and 5(b), as well as the additional results for the $p$-type substrate, is to invoke an interfacial reflection coefficient that is significantly different for non-nitrided and fullynitrided $\mathrm{Si}-\mathrm{SiO}_{2}$ interfaces. One rationale for this type of effect has its origin in effects well-known in physical optics, where thin surface layers of transparent materials with different optical indices of refraction will either enhance or reduce surface reflectivity, and thereby reduce or enhance, respectively, the optical transmission independent of the surface on which the light is incident. The optical path length for these surface layers must be in the range of about onequarter of the optical wavelength in the surface layer material. For this type of mechanism to apply to the nitrided oxide dielectrics, the monolayer nitridation would have to have an effective index of refraction higher than that of the oxide surface. Stated differently, the reduced tunneling mechanism would have to rely on a significant phase shift for the electron transport in the nitrided layer relative to that of the non-nitrided interface. This type of contribution to the tunneling transport needs additional theorectical and experimental study 


\section{B. Unique chemical bonding in plasma-deposited nitride layers}

As has already been shown in Sec. III B, the nitride films prepared by $300{ }^{\circ} \mathrm{C}$, and subsequently subjected to a $900{ }^{\circ} \mathrm{C}$ RTA display interesting behavior in regard to $\mathrm{H}$ loss as well as $\mathrm{Si}-\mathrm{N}$ formation. The explanation for the unexpected electrical properties of these films, that has evolved from a combination of the IR studies and electrical data is best illustrated in Fig. 8. The $x$ axis of this figure is obtained from IR data, and the $y$ axis from electrical data on MOS capacitors. The decrease of $V_{\mathrm{FB}}$ to its expected value in films annealed at $900{ }^{\circ} \mathrm{C}$ is indicative of decreases in fixed dielectric positive charge, i.e., reductions in defects in the nitride film. Therefore this figure demonstrates that the formation of additional $\mathrm{Si}-\mathrm{N}$ bonds from bonding groups that have loose $\mathrm{H}$ atoms is responsible for the improved behavior.

To best understand the unique attributes of the two-step process for forming device-quality nitride films with low bulk defect densities, it is necessary to contrast the bonding changes that take place in these films as a function of processing, with the bonding in nitride films prepared by conventional higher temperature $\left(\mathrm{T}>500{ }^{\circ} \mathrm{C}\right) \mathrm{LPCVD}$ processes. Summarizing the IR data presented above: (i) as-deposited silicon nitride films are Si:N:H alloys with an average number of bonds/atom $(\sim 2.7)$ which is essentially the same as deposited $\mathrm{SiO}_{2}$; (ii) these films are therefore low defect continuous random network structures with low bulk defect densities, primarily because of their high $\mathrm{H}$-atom content $(\sim 30$ at. \%); (iii) these films contain several kinds of bonded $\mathrm{H}$ : (a) in nearest-neighbor $\mathrm{SiH} / \mathrm{SiNH}$ and $\mathrm{SiNH} / \mathrm{SiNH}$ pairs, and (b) in isolated SiNH groups; (iv) upon annealing to $500{ }^{\circ} \mathrm{C}, \mathrm{H}$ is released from these nearest-neighbor groups leading to defect formation as both Si- and $\mathrm{N}$-atom dangling bonds; (v) upon further annealing at temperature $>500{ }^{\circ} \mathrm{C}, \mathrm{H}$ evolution continues, but additional $\mathrm{Si}-\mathrm{N}$ bonds are formed; (vi) the formation of additional $\mathrm{Si}-\mathrm{N}$ bonds from bonding sites that have lost $\mathrm{H}$ atoms reduces bulk defect densities accounting for the unique electrical properties of the films. In effect the special bonding arrangements in which $\mathrm{H}$ atoms are nearestnetwork neighbors in the as deposited films is the key to the unique behavior. For example, these bonding sites are the reason for poor performance in films annealed to $500{ }^{\circ} \mathrm{C}$, but are the reason for improvements in performance in films that have been annealed to $900{ }^{\circ} \mathrm{C}$. The IR spectra of Ref. 12 clearly indicate that additional Si-N bonds are formed after the $900^{\circ} \mathrm{C}$ anneal; however, at this time we offer no microscopic model for the atomic motions that are involved in these relaxation processes.

It is found in Ref. 12 that the nitride films contain bonded hydrogen after $900{ }^{\circ} \mathrm{C}$. This is mostly in isolated bonding arrangements in SiNH bonding arrangements. The bonding energy of the HN bond in a SiNH group is in excess of $5 \mathrm{eV}$. As an isolated bonding arrangement, this site will not be an electronically active defect, although under certain conditions it may act as a defect precursor. One pathway for defect generation is through hole trapping and the formation of an ammonium center. However, at the low bias voltages that are contemplated for the stacked ON gate dielectrics, hole injection into the nitride layer is unlikely.

In contrast, films prepared by LPCVD at temperatures in excess of $500{ }^{\circ} \mathrm{C}$ contain only small concentrations of bonded $\mathrm{H}$, and in order to form a network comprised of threefold coordinated $\mathrm{N}$ atoms and fourfold coordinated $\mathrm{Si}$ atoms, these films must contain significant numbers of both $\mathrm{Si}-$ and $\mathrm{N}$-atom dangling bond defects. Entropy considerations require that these defects be distributed throughout the network rather than occurring as nearest-neighbors. Since silicon-nitride films do not display a viscoelastic relaxation, these bonding defects cannot recombine, as in the films produced at lower temperature by remote plasma processing, and therefore the films have high defect densities even after higher temperature processing. The only way that defects in these films can be reduced in density is by postdeposition annealing in an oxygen containing ambient as shown by the recent results reported by the University of Texas at Austin Group. ${ }^{19}$ Films prepared in this way are oxynitride alloys with dielectric constants below those of silicon nitride. Oxynitride alloy films have been incorporated into FETs, but in general this leads to significant reductions in peak channel mobilities in NMOS devices. ${ }^{20}$

\section{Stopping power of nitride layers for B-atom diffusion}

The stopping power of nitride films prepared by remote plasma processing and subsequent RTAs is simply associated with the high areal density of $\mathrm{N}$ atoms obtained in this way. The areal density of $\mathrm{N}$ atoms in a film that is $0.8 \mathrm{~nm}$ thick is estimated to be $4-5 \times 10^{15} \mathrm{~cm}^{-2}$. Since the bonding radius of $\mathrm{N}$ atoms is $\sim 0.8 \mathrm{~nm}$, this means that the fractional area coverage of these $\mathrm{N}$ atoms is $\sim 0.8-1.0$. Since it has been shown that the diffusion of $\mathrm{B}$ atoms through oxide films involves $\mathrm{B}-\mathrm{O}$ bond formation, the $0.8 \mathrm{~nm}$ nitride film effectively screens the $\mathrm{B}$ atoms from the $\mathrm{O}$ atoms in the underlying oxide film of the stacked ON dielectric. ${ }^{21}$ Reducing the nitride thickness to $\sim 0.4 \mathrm{~nm}$ reduces the fractional coverage to $0.4-0.5$, enabling the $\mathrm{B}$ atoms to interact with the underlying oxide layer, and be transported to the Si substrate where they can degrade electrical performance. As anticipated, increasing the nitride layer to $1.2 \mathrm{~nm}$, as in the FETs described above will then not only reduce direct tunneling, but also improve resistance to B-atom penetration in PMOS devices.

\section{SUMMARY}

This article has indicated a processing pathway to the formation of ultrathin nitrided gate oxides that can play a significant role in advanced FET devices. By using $300^{\circ} \mathrm{C}$ plasma assisted processing including: (i) oxidation and nitridation to form nitride interfaces and an ultrathin oxide film $(\sim 0.5-0.6 \mathrm{~nm}$ thick) that serves as a platform for further film deposition, and (ii) film deposition forms ultrathin oxide, nitride, or stacked ON dielectrics, in combination with low thermal budget RTAs (typically $30 \mathrm{~s}$ at $900{ }^{\circ} \mathrm{C}$ ), it has been shown that device-quality ultrathin gate dielectrics can 
be formed. The interface nitridation and ON stacked dielectrics have been demonstrated to yield improved behavior with respect to ultrathin oxides in NMOS devices with oxide equivalent thickness down to $1.8 \mathrm{~nm}$. Extensions of this approach, based on the calculation of tunneling currents in stacked ON devices suggests that the stacked ON dielectrics can be used for several device generations, in particular for $t_{\mathrm{ox} \text { eq }}$ extending down to at least $1.5 \mathrm{~nm}$, and perhaps to 1.2 $\mathrm{nm}$. The stacked ON gate dielectrics with at least $0.8 \mathrm{~nm}$ of nitride have shown excellent resistance to B-atom transport out of $p^{+}$polycrystalline silicon gate electrodes. Since the top surface nitridation process also nitrides the $\mathrm{Si}-\mathrm{SiO}_{2}$ interface, ${ }^{22}$ the channel mobilities of holes in PMOS devices may be degraded by the use of these structures.

\section{ACKNOWLEDGMENTS}

This work was supported in part by the NSF Engineering Research Center for Advanced Electronic Materials Processing at North Carolina State University, the Office of Naval Research, and the Semiconductor Research Corporation.

${ }^{1}$ D. Mathiot, A. Straboni, E. Andre, and P. Debenest, J. Appl. Phys. 73, 8215 (1993); J. Ahn, J. Kim, G. Q. Lo, and D.-L. Kwong, Appl. Phys. Lett. 60, 2089 (1992).

${ }^{2}$ M. L. Green, in Fundamental Aspects of Ultrathin Dielectrics in Si-based Devices, edited by E. Garfunkel, E. Gusev, and A. Vul (NATO, in press).

${ }^{3}$ D. R. Lee, G. Lucovsky, M. R. Denker, and C. Magee, J. Vac. Sci. Technol. A 13, 1671 (1995).

${ }^{4}$ D. R. Lee, C. R. Parker, J. R. Hauser, and G. Lucovsky, J. Vac. Sci. Technol. B 13, 1778 (1995).
${ }^{5}$ Y. Ma, T. Yasuda, and G. Lucovsky, Appl. Phys. Lett. 64, 2226 (1994).

${ }^{6} \mathrm{~S}$. V. Hattangady et al., Tech. Dig. Int. Electron Devices Meet. 495 (1996).

${ }^{7}$ Y. Wu, G. Lucovsky, and H. Z. Massoud, Proc. IEEE Reliab. Phys. Symp. (in press).

${ }^{8}$ C. G. Parker, G. Lucovsky, and J. R. Hauser, IEEE Electron Device Lett. 19, 106 (1988).

${ }^{9}$ T. Yasuda, Y. Ma, S. Habermehl, and G. Lucovsky, Appl. Phys. Lett. 60, 434 (1992).

${ }^{10}$ G. Lucovsky, H. Niimi, K. Koh, D. R. Lee, and Z. Jing, The Physics and Chemistry of $\mathrm{SiO}_{2}$ and the $\mathrm{Si}-\mathrm{SiO}_{2}$ Interface, edited by $\mathrm{H}$. Z. Massoud, E. H. Poindexter, and C. R. Helms (Electrochemical Society, Pennington, NJ, 1996), p. 441.

${ }^{11} \mathrm{M}$. Kushner (private communication).

${ }^{12}$ Z. Lu, M. J. Williams, P. F. Santos-Filho, and G. Lucovsky, J. Vac. Sci. Technol. A 13, 607 (1995).

${ }^{13}$ G. Lucovsky, P. Santos-Filho, G. Stevens, Z. Jing, and A. Banerjee, J. Non-Cryst. Solids 198-200, 19 (1996).

${ }^{14}$ G. Lucovsky and J. C. Phillips, J. Non-Cryst. Solids (in press).

${ }^{15}$ Y. Ma, T. Yasuda, and G. Lucovsky, J. Vac. Sci. Technol. A 11, 952 (1993); Y. Ma, T. Yasuda, S. Habermehl, and G. Lucovsky, J. Vac. Sci. Technol. B 11, 1533 (1993).

${ }^{16}$ H. Yang, H. Niimi, and G. Lucovsky, J. Appl. Phys. 83, (1998).

${ }^{17}$ G. Lucovsky, H. Yang, and H. Z. Massoud, J. Vac. Sci. Technol. B 16, (1998). (1998).

${ }^{18}$ G. Lucovsky, A. Banerjee, B. Hinds, B. Claflin, K. Koh, and H. Yang, J. Vac. Sci. Technol. B 15, 1074 (1997).

${ }^{19}$ B. Y. Kim, H. F. Luan, and D. L. Kwong, Tech. Dig. Int. Electron Devices Meet. 97, 463 (1997).

${ }^{20}$ E. M. Vogel, Ph.D thesis, Department of Electrical and Computer Engineering, North Carolina State University, 1998.

${ }^{21}$ R. Fair, IEEE Electron Device Lett. 18, 244 (1997).

${ }^{22}$ Y. Ma, T. Yasuda, and G. Lucovsky, Mater. Res. Soc. Symp. Proc. 303, 325 (1993). 